\title{
Low-dose inhaled and nasal corticosteroid use and the risk of cataracts
}

\author{
P. Ernst $^{\star, \#}$, M. Baltzan*, ${ }^{\star,+}$, J. Deschênes ${ }^{\S}$ and S. Suissa*,
}

\begin{abstract}
Orally inhaled corticosteroid use has been convincingly linked to an increase in the risk of cataracts, although the risk at lower doses in common use remains uncertain. The potential risk of cataracts with the use of nasal corticosteroids is unknown.

A matched nested case-control analysis was performed in a population-based cohort of elderly people who had been dispensed medications for airway disease, as identified through a universal drug benefit plan.

Inhaled corticosteroid use was associated with a dose-related increase in both the risk of all cataracts and severe cataracts requiring extraction, and the increase in risk of severe cataracts was apparent even at daily doses of $\leqslant \mathbf{5 0 0} \mu \mathrm{g}$. An excess risk with nasal corticosteroids was not apparent for severe cataracts.

It is concluded that, among the elderly, even low doses of inhaled corticosteroids are associated with a small but significant excess risk of cataracts requiring extraction. Such an excess risk was not observed with nasal corticosteroids.
\end{abstract}

KEYWORDS: Asthma, cataracts, chronic obstructive pulmonary disease, elderly, inhaled corticosteroids, nasal corticosteroids

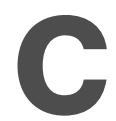

ataracts are a major public health problem, affecting almost $50 \%$ of adults aged $>65 \mathrm{yrs}$, and cataract extraction is the most common surgical procedure carried out in the USA [1]. Furthermore, it has been estimated that, by delaying the development of cataract formation by $10 \mathrm{yrs}, 45 \%$ of these extractions would be avoided [2]. The use of orally inhaled corticosteroids (ICSs) has been convincingly linked to an increase in the risk of cataracts in several epidemiological studies [3-5].

CUMMING et al. [3] undertook the screening of a general population for cataracts and demonstrated a clear association between the use of ICSs and cataracts. The validity of this association was enhanced by the finding of a dose-related increase in the risk of posterior subcapsular cataracts, a particularly debilitating type of cataract [1]. Of particular concern was a more than two-fold increase in risk at daily doses of 200-400 g. day ${ }^{-1}$ beclomethasone, doses recommended for the large population with mild persistent asthma [6]. The doses of ICS were based on patient report, however, thus raising doubts as to the real doses used by patients. GARBE et al. [4] found an increase in the risk of all cataracts combined, which was particularly evident at daily doses of beclomethasone of $>1,000 \mu \mathrm{g}$, whereas the risk associated with lower doses was uncertain. In a large general practice research database in the UK, JICK et al. [5] found a dose-related increase in the risk of cataracts in subjects aged $\geqslant 40$ yrs. The risk appeared to be increased even at a prescribed dose of ICS of $<500 \mathrm{~g} \cdot$ day $^{-1}$ beclomethasone. The limitations of this study include: the exclusion of subjects who had been prescribed oral or nasal corticosteroids (NCSs), thus limiting the ability to generalise the results to a significant proportion of patients with airway disease; and the derivation of doses from prescriptions rather than drugs dispensed, thus adding uncertainty about the doses consumed. Therefore, the doses associated with an increase in risk can be questioned. None of these studies examined the independent risk of cataracts associated with the use of NCSs. Furthermore, in all three studies, beclomethasone was responsible for the preponderance of exposure to ICSs, with few, if any, patients receiving fluticasone, now a commonly prescribed medication in North America, and a medication for which concerns regarding a greater potential for systemic effects have been raised $[7,8]$.

In the present study, the association between the risk of cataracts among elderly subjects and the dispensing of low doses of ICS, as well as the risk associated with use of NCSs, was examined using a large population-wide claims database.
AFFILIATIONS

*Division of Clinical Epidemiology and

${ }^{\S}$ Dept of Ophthalmology, Royal Victoria Hospital, and

"Division of Respiratory Medicine, McGill University Health Center,

"Dept of Epidemiology and

Biostatistics and of Medicine, McGill University, and

${ }^{+}$Dept of Respiratory Medicine, Mount Sinai Hospital and Respiratory Medicine Service, Fleury Hospital Centre, Montreal, QC. Canada.

CORRESPONDENCE

P. Ernst

Division of Clinical Epidemiology

Royal Victoria Hospital

687 Pine Avenue West

Ross 4.29

Montreal

Québec H3A 1 A1

Canada

Fax: 15148431493

E-mail:

Pierre.ernst@clinepi.mcgill.ca

Received:

April 112005

Accepted after revision:

January 202006

\section{SUPPORT STATEMENT}

This study was funded by a grant from the Fonds de la Recherche en Santé du Québec (Montreal, QC, Canada). S. Suissa is the recipient of a Distinguished Investigator award from the Canadian Institutes of Health Research (Ottawa, ON, Canada). 


\section{METHODS}

\section{Source of data}

The health databases of the Régie de l'assurance maladie du Québec, the agency responsible for administering the universal health insurance programme of the province of Quebec, Canada, were used. The databases contain information on demographics, all medical services rendered, along with the diagnostic code of the service (International Classification of Diseases, ninth revision (ICD-9) code), and, for people aged $\geqslant 65$ yrs, all outpatient prescription medications dispensed. Information obtained from the Quebec prescription claims databases has been previously validated [9].

\section{Study design}

A population-based cohort design with nested case-control analysis was used. The source population consisted of all subjects who, between January 1, 1988 and December 31, 2001, were aged $\geqslant 65$ yrs and were dispensed, during this period, at least one of the following respiratory medications: any form of $\beta$-agonist; theophylline; ipratropium bromide; sodium cromoglycate; nedocromil; ketotifen; leukotriene antagonists; or ICSs. A cohort was formed from this source population by identifying all subjects with three or more prescriptions for these medications in any 1-yr period and on at least two different dates. Cohort entry was taken as the date of the third prescription. In order to ensure a minimum of $4 \mathrm{yrs}$ of information on use of medications and to limit the study, as far as possible, to incident cases of cataract, the current study was limited to subjects with $\geqslant 4$ yrs of follow-up and without a diagnosis of cataract or a cataract extraction during this initial 4-yr period.

Cases of cataracts were the cohort members with a first diagnosis of cataract (ICD-9 code 366) or a procedure code for cataract extraction during follow-up. The subset of cases with severe cataracts, defined as a cataract requiring an extraction within 2 yrs from first diagnosis, were also defined.

For each case, four controls were selected randomly from among subjects who entered the cohort during the same month and year as the case and who were born within 6 months of the birth date of the case. For the cases for whom controls could not be found, matching was broadened to the year of cohort entry rather than month and year. Controls also had to be at risk on the date of the outcome event in the corresponding case (the index date), i.e. they could not have been identified as having a cataract, moved from the province or died as of this date. This date was taken as the index date for the controls.

\section{Corticosteroid exposure}

All prescriptions of corticosteroid medications dispensed during the 4 yrs prior to the index date were obtained for all cases and controls, and classified according to their formulation, dose, quantity, duration and date of dispensing. These included: beclomethasone, budesonide, triamcinolone, fluticasone and flunisolide (in inhaled and nasal forms); and hydrocortisone, cortisone, prednisone, prednisolone, triamcinolone, methylprednisolone, betamethasone and dexamethasone (in oral form).

In order to combine the different corticosteroids, dose equivalencies were established. For oral corticosteroids, the dose equivalencies were taken directly from HAYNES [10]. The equivalent doses are: prednisone $5 \mathrm{mg}$; prednisolone $5 \mathrm{mg}$; hydrocortisone $20 \mathrm{mg}$; cortisone $25 \mathrm{mg}$; triamcinolone $4 \mathrm{mg}$; methylprednisolone $4 \mathrm{mg}$; betamethasone $0.75 \mathrm{mg}$; and dexamethasone $0.75 \mathrm{mg}$. The estimation of equivalencies for ICSs and NCSs were chosen on the basis of relative topical potency and what experts consider to be comparable low doses, according to the National Asthma Education Program expert panel II report [11] and the Canadian asthma consensus statement summary [12]. Accordingly, the equivalent doses for ICSs and NCSs are beclomethasone $100 \mu \mathrm{g}$, budesonide $80 \mu \mathrm{g}$, triamcinolone $200 \mu \mathrm{g}$, fluticasone $50 \mu \mathrm{g}$ and flunisolide $200 \mu \mathrm{g}$.

\section{Covariates}

The covariates used included sex, hospitalisation in the previous 4 yrs and severity of respiratory disease, as well as other conditions or medications associated with the risk of cataracts [1]. The severity of respiratory disease was quantified independently of ICS use, by counting the number of dispensed prescriptions of $\beta$-agonists, ipratropium bromide and theophylline. The concurrent use of oral corticosteroids was assessed as the cumulative prednisone equivalent dose dispensed during the $4-y r$ period prior to the index date.

Comorbid disease was identified by the dispensing of diseasespecific medications. Diabetes was identified by prescriptions for insulin and oral hypoglycaemic drugs. Cardiovascular drugs included cardiotropes and vasodilators. Hypertension was identified by the dispensing of antihypertensives, not including diuretics. Since diuretics are used so extensively, these were considered as a distinct risk factor. Rheumatic drugs included gold salts, methotrexate, azathioprine, hydroxychloroquine and chloroquine. Adjustment was also carried out for the use of medications that have been specifically associated with the risk of cataract, such as nonrespiratory topical corticosteroids, allopurinol and major tranquilisers [1, 13]. For adjustment purposes, exposure to these drugs was considered as present or absent based on whether or not they had been dispensed at any time during the prior 4-yr period.

\section{Statistical analysis}

All analyses were based on techniques for matched data. The primary analysis was based on corticosteroid exposure during the 4-yr period prior to the index date, with non-use during the 4 -yr period as the reference. Conditional logistic regression was used to calculate crude and adjusted odds ratios for ICS and NCS use in relation to the occurrence of cataracts and severe cataracts. In a nested case-control study, such as the present one, the odds ratios correctly estimate the incidence ratios [14]. A cumulative dose during the 4-yr span was computed by summing separately the dose equivalents of all prescriptions of inhaled and nasal formulations. The mean daily dose was taken as the cumulative dose divided by the time from the date of the first prescription to the index date.

Age and calendar time were inherently accounted for by the matching. Further adjustment factors included sex, prior hospitalisation and severity of respiratory disease, as well as all other covariates measuring conditions associated with the risk of cataract. Since oral corticosteroid use is clearly associated with an increased risk of cataract [1], separate analyses were carried out among subjects with and without 
exposure to oral corticosteroids in the prior $4 \mathrm{yrs}$. When examining the risk associated with ICSs, adjustment was carried out for use of NCSs and vice versa.

\section{RESULTS}

The cohort comprised 101,805 subjects, including 27,708 cases with a first diagnosis of cataract or a cataract extraction, of whom 10,754 were considered severe. Characteristics of cases and controls are provided in table 1 . Information is provided for all cases and their respective controls, as well as for the more severe cases that resulted in surgical extraction within 2 yrs of the diagnosis. The subjects were elderly, with a mean age of almost $78 \mathrm{yrs}$. Cases tended to have more comorbid disease, although the differences were small. Cases had been dispensed more ophthalmic corticosteroids and eye drops than their respective controls. Cumulative exposure to oral corticosteroids over the prior 4 yrs had been significantly greater among cases.

In table 2, the relative risk (RR) of any cataract appears to be increased for both ICSs and NCSs after adjustment for comorbidity, each other and exposure to oral corticosteroids. For ICSs, the risk is increased significantly, even at doses of $<500 \mu \mathrm{g} \cdot$ day $^{-1}$ beclomethasone equivalents (RR 1.11; 95\% confidence interval (CI) 1.07-1.14), and rises to a maximum increase of $44 \%$ (RR $1.44 ; 95 \%$ CI $1.31-1.57$ ) at doses of 1,500 $2,000 \mu \mathrm{g} \cdot \mathrm{day}^{-1}$. Overall, the risk of any cataract with the use of ICSs increases by $19 \%$ (RR 1.19; 95\% CI 1.15-1.23) per additional $1,000 \mu \mathrm{g} \cdot \mathrm{day}^{-1}$ beclomethasone or equivalent. For
NCSs, there is also an apparent increase in risk, even at doses of $<100 \mu \mathrm{g} \cdot \mathrm{day}^{-1}$ (RR 1.16; 95\% CI 1.12-1.21), although, in contrast to the orally inhaled route, the dose response is less obvious.

The dose-response analyses were repeated for the more severe cases of cataracts, which required surgical extraction in the 2 yrs following diagnosis (table 3). The increases in risk seen with ICSs are quite similar to those observed for all cataracts; there is a $24 \%$ increase in risk of a severe cataract (RR $1.24 ; 95 \%$ CI 1.18-1.31) per $1,000 \mu \mathrm{g} \cdot \mathrm{day}^{-1}$ beclomethasone or equivalent, and the increase in risk is apparent even at doses of $\leqslant 500 \mu \mathrm{g} \cdot \mathrm{day}^{-1}$ (RR 1.14; 95\% CI 1.08-1.20). For NCSs, however, there was no significant increase in the risk of severe cataracts.

Fluticasone accounted for $14.9 \%$ of the prescriptions of ICSs among the controls. There was no difference in the risk of severe cataracts for users of fluticasone (RR 1.12; $95 \% \mathrm{CI}$ 1.04-1.19) compared with users of any ICS (RR 1.19; $95 \% \mathrm{CI}$ 1.13-1.25).

Table 4 provides an analysis of the risk of any cataract for various doses of ICS among subjects who have, or have not, been dispensed oral corticosteroids in the previous 4 yrs. Although the dose response appears somewhat steeper among subjects also dispensed oral corticosteroids, the risk of any cataract remains elevated, even among subjects without such exposure. Among subjects without concomitant exposure to oral corticosteroids, there is a $12 \%$ increase in the risk of any

\section{TABLE 1 Characteristics of cases and controls}

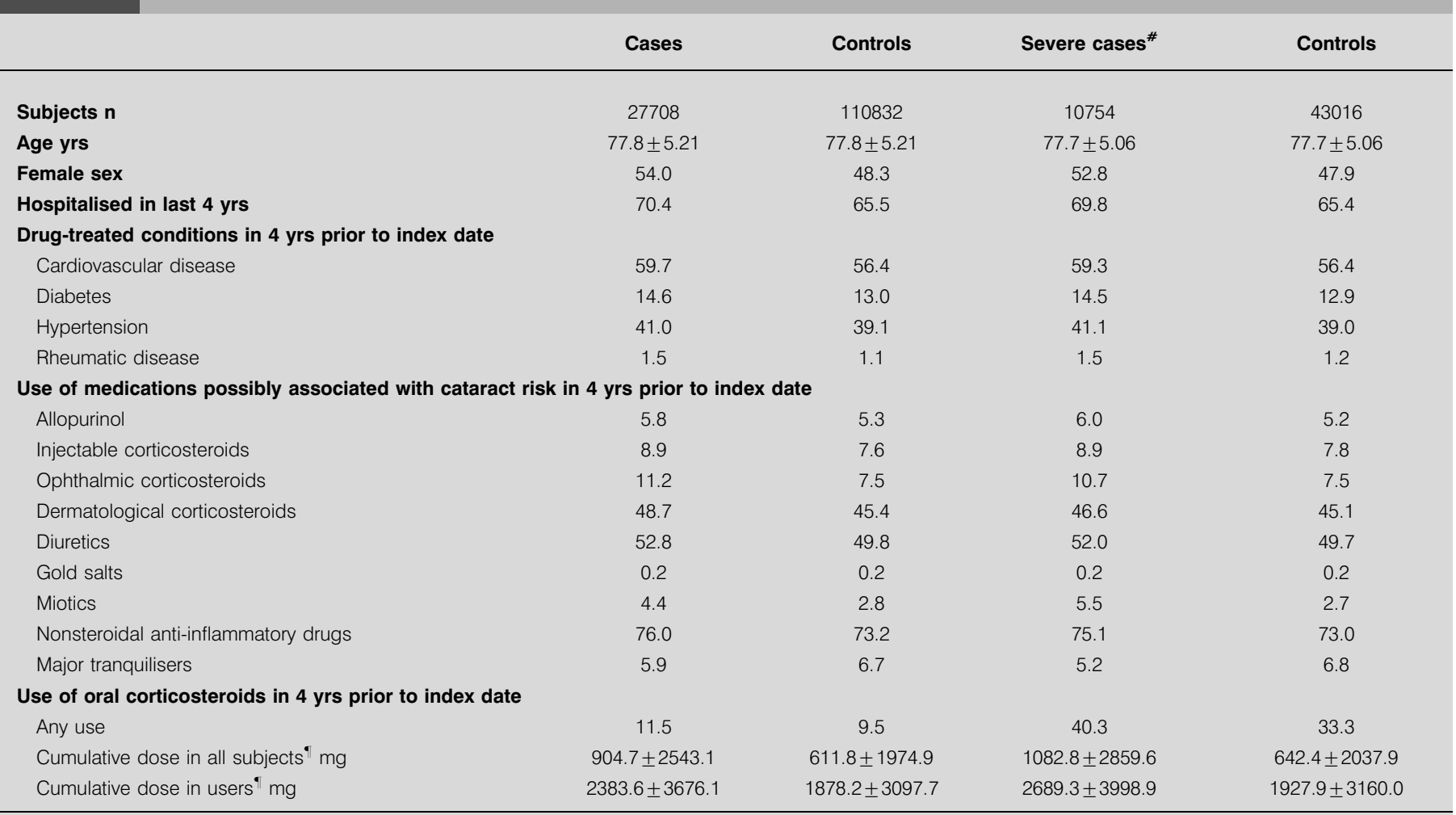

Data are presented as mean \pm SD or percentages. ${ }^{*}$ : requiring cataract extraction within 2 yrs of the diagnosis; ${ }^{\bullet}$ : in prednisone equivalents. 
TABLE 2 Crude and adjusted relative risk (RR) of any cataract for the mean daily dose of inhaled (ICS) and nasal corticosteroid (NCS) in the 4-yr period prior to the index date

\begin{tabular}{|c|c|c|c|c|}
\hline & Cases & Controls & Crude RR & Adjusted $^{\#}$ RR (95\% Cl) \\
\hline Subjects n & 27708 & 110832 & & \\
\hline ICS dose $\mu \mathrm{g} \cdot$ day $^{-1}$ & $342.1 \pm 476.1$ & $299.0 \pm 448.5$ & 1.24 & $1.19(1.15-1.23)^{\bullet}$ \\
\hline \multicolumn{5}{|l|}{ Range (mean) of ICS dose ${ }^{+} n$} \\
\hline $0(0) \mu \mathrm{g} \cdot \mathrm{day}^{-1}$ & 10176 & 45662 & 1.0 & 1.0 (reference) \\
\hline$>0-500$ (196) $\mu \mathrm{g} \cdot \mathrm{day}^{-1}$ & 10199 & 39600 & 1.17 & $1.11(1.07-1.14)$ \\
\hline$>1500-2000(1701) \mu \mathrm{g} \cdot$ day $^{-1}$ & 788 & 2370 & 1.55 & $1.44(1.31-1.57)$ \\
\hline$>2000$ (2458) $\mu \mathrm{g} \cdot \mathrm{day}^{-1}$ & 217 & 677 & 1.50 & $1.36(1.16-1.59)$ \\
\hline NCS dose $\mu \mathrm{g} \cdot$ day $^{-1}$ & $17.3 \pm 57.2$ & $14.1 \pm 51.2$ & 1.11 & $1.08(1.05-1.10)^{\bullet}$ \\
\hline \multicolumn{5}{|l|}{ Range (mean) of NCS dose ${ }^{+} n$} \\
\hline $0(0) \mu \mathrm{g} \cdot \mathrm{day}^{-1}$ & 21556 & 90265 & 1.0 & 1.0 (reference) \\
\hline$>0-100(34) \mu \mathrm{g} \cdot$ day $^{-1}$ & 4649 & 15714 & 1.24 & $1.16(1.12-1.21)$ \\
\hline
\end{tabular}

Data are presented as mean \pm SD or absolute values. Cl: confidence interval. ${ }^{\#}$ : for all factors in table 1 , as well as the cumulative dose of the other class of topical corticosteroids; " : per additional $1,000 \mu \mathrm{g} \cdot$ day $^{-1}$ ICS or $100 \mu \mathrm{g} \cdot$ day $^{-1} \mathrm{NCS}$ (beclomethasone equivalents); ${ }^{*}$ : among controls in category in beclomethasone equivalents.

TABLE 3 Crude and adjusted relative risk (RR) of severe cataracts for the mean daily dose of inhaled (ICS) and nasal corticosteroid (NCS) in the 4-yr period prior to the index date

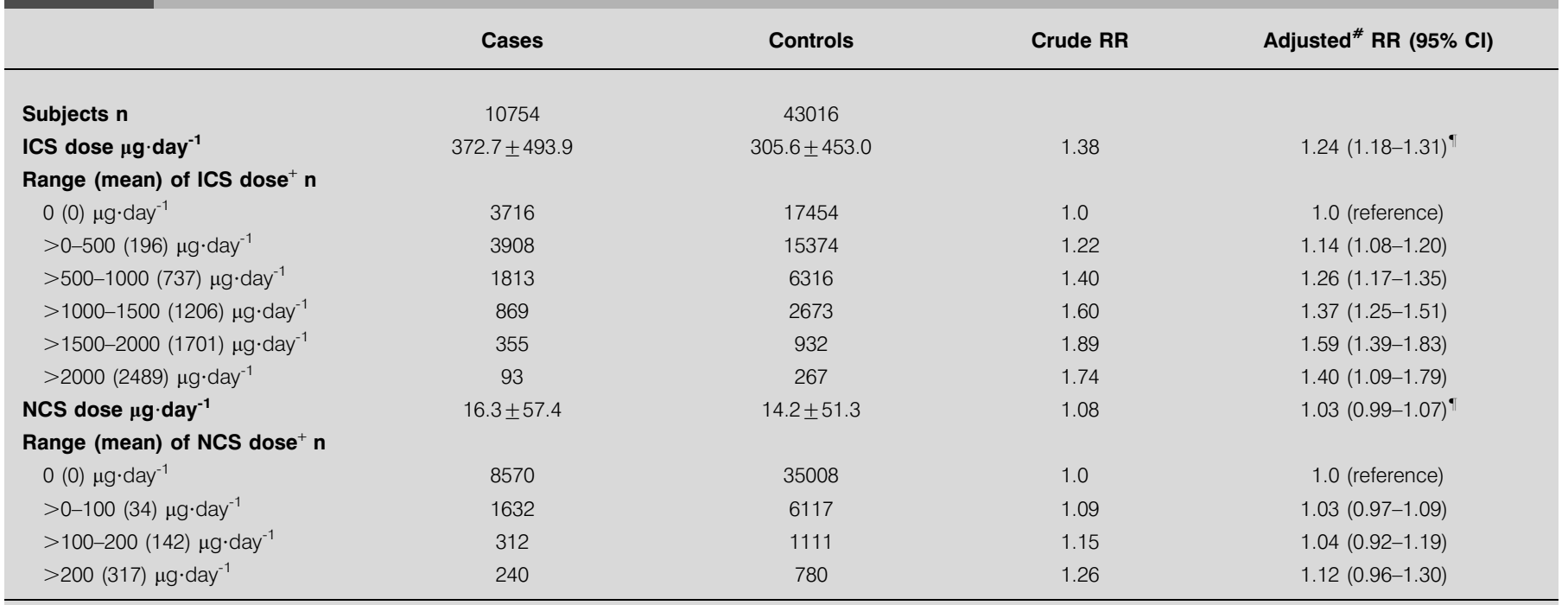

Data are presented as mean \pm SD or absolute values. Cl: confidence interval. \#: for all factors in table 1 , as well as the cumulative dose of the other class of topical corticosteroids; " : per additional $1,000 \mu \mathrm{g} \cdot$ day $^{-1}$ ICS or $100 \mu \mathrm{g} \cdot$ day $^{-1}$ NCS (beclomethasone equivalents); ${ }^{+}$: among controls in category in beclomethasone equivalents

cataract (RR $1.12 ; 95 \%$ CI $1.07-1.18$ ) per $1,000 \mu \mathrm{g} \cdot$ day $^{-1}$ beclomethasone or equivalent. The association is of a similar magnitude when considering only severe cataracts, as shown in table 5 .

\section{DISCUSSION}

An increase in the risk of cataracts, including severe cataracts requiring surgical extraction, has been shown in association with the dispensing of ICSs among elderly patients. Although the excess risk was small, it increased significantly with increasing dose and was present even at $\leqslant 500 \mu \mathrm{g} \cdot \mathrm{day}^{-1}$ beclomethasone or equivalent dose of other ICSs. There was no evidence of an excess risk associated with the orally inhaled form of fluticasone compared with other orally ICSs, mainly beclomethasone and budesonide. The relationship between the risk of cataracts and use of NCSs was less apparent. The dose 
TABLE 4 Relative risk (RR) of any cataract for the mean daily dose of orally inhaled corticosteroid dispensed in 4-yr period prior to the index date, stratified by use of oral corticosteroids

\begin{tabular}{|c|c|c|c|c|}
\hline & Cases & Controls & Crude RR & Adjusted $^{\#}$ RR (95\% Cl) \\
\hline \multicolumn{5}{|c|}{ Subjects with no oral CS use } \\
\hline Subjects $n$ & 17191 & 74733 & & \\
\hline \multicolumn{5}{|l|}{ ICS dose range ${ }^{+} n$} \\
\hline $0 \mu \mathrm{g} \cdot$ day $^{-1}$ & 8968 & 41278 & 1.0 & 1.0 (reference) \\
\hline$>0-500 \mu \mathrm{g} \cdot \mathrm{day}^{-1}$ & 5988 & 24193 & 1.16 & $1.13(1.09-1.17)$ \\
\hline$>1000-1500 \mu \mathrm{g} \cdot$ day $^{-1}$ & 530 & 2100 & 1.20 & $1.21(1.09-1.33)$ \\
\hline$>1500-2000 \mu \mathrm{g} \cdot$ day $^{-1}$ & 207 & 772 & 1.27 & $1.28(1.09-1.50)$ \\
\hline$>2000 \mu \mathrm{g} \cdot \mathrm{day}^{-1}$ & 31 & 192 & 0.77 & $0.78(0.53-1.14)$ \\
\hline \multicolumn{5}{|l|}{ Subjects with oral CS use } \\
\hline Subjects n & 10517 & 36099 & & \\
\hline ICS dose $\mu \mathrm{g} \cdot$ day $^{-1}$ & $600 \pm 541$ & $557 \pm 520$ & 1.19 & $1.20(1.15-1.26)^{\bullet}$ \\
\hline \multicolumn{5}{|l|}{ ICS dose range ${ }^{+} n$} \\
\hline$>1000-1500 \mu \mathrm{g} \cdot$ day $^{-1}$ & 1457 & 4568 & 1.20 & $1.23(1.12-1.35)$ \\
\hline$>1500-2000 \mu \mathrm{g} \cdot$ day $^{-1}$ & 581 & 1598 & 1.38 & $1.43(1.27-1.61)$ \\
\hline$>2000 \mu \mathrm{g} \cdot \mathrm{day}^{-1}$ & 186 & 485 & 1.47 & $1.48(1.23-1.79)$ \\
\hline
\end{tabular}

Data are presented as mean \pm SD or absolute values. Cl: confidence interval; CS: corticosteroid; ICS: inhaled corticosteroid. \#: for all factors in table 1 , as well as the cumulative dose of nasal corticosteroids; ": per additional $1,000 \mu \mathrm{g} \cdot$ day $^{-1}$ ICS (beclomethasone equivalents); ${ }^{+}$: among controls in category in beclomethasone equivalents.

TABLE 5 Relative risk (RR) of severe cataracts for the mean daily dose of orally inhaled corticosteroid used in the 4-yr period prior to index date, stratified by use of oral corticosteroids

\begin{tabular}{|c|c|c|c|c|}
\hline & Cases & Controls & Crude RR & Adjusted ${ }^{\#}$ RR $(95 \% \mathrm{Cl})$ \\
\hline \multicolumn{5}{|c|}{ Subjects with no oral CS use } \\
\hline Subjects $n$ & 6424 & 28682 & & \\
\hline \multicolumn{5}{|l|}{ ICS dose range ${ }^{+} n$} \\
\hline $0 \mu \mathrm{g} \cdot \mathrm{day}^{-1}$ & 3261 & 15692 & 1.0 & 1.0 (reference) \\
\hline$>0-500 \mu \mathrm{g} \cdot \mathrm{day}^{-1}$ & 2254 & 9322 & 1.19 & $1.15(1.08-1.22)$ \\
\hline$>1000-1500 \mu \mathrm{g} \cdot$ day $^{-1}$ & 209 & 831 & 1.27 & $1.23(1.05-1.45)$ \\
\hline$>1500-2000 \mu \mathrm{g} \cdot \mathrm{day}^{-1}$ & 81 & 287 & 1.42 & $1.33(1.03-1.72)$ \\
\hline$>2000 \mu \mathrm{g} \cdot \mathrm{day}^{-1}$ & 10 & 71 & 0.71 & $0.66(0.34-1.29)$ \\
\hline \multicolumn{5}{|l|}{ Subjects with oral CS use } \\
\hline Subjects $n$ & 4330 & 14334 & & \\
\hline ICS dose $\mu \mathrm{g} \cdot$ day $^{-1}$ & $636 \pm 550$ & $562 \pm 525$ & 1.33 & $1.27(1.18-1.36)^{\bullet}$ \\
\hline$>1000-1500 \mu \mathrm{g} \cdot$ day $^{-1}$ & 660 & 1842 & 1.46 & $1.39(1.20-1.60)$ \\
\hline$>1500-2000 \mu \mathrm{g} \cdot \mathrm{day}^{-1}$ & 274 & 645 & 1.77 & $1.66(1.38-2.00)$ \\
\hline$>2000 \mu \mathrm{g} \cdot \mathrm{day}^{-1}$ & 83 & 196 & 1.78 & $1.60(1.20-2.13)$ \\
\hline
\end{tabular}

Data are presented as mean \pm SD or absolute values. Cl: confidence interval; CS: corticosteroid; ICS: inhaled corticosteroid. ${ }^{\#}$ : for all factors in table 1 , as well as the cumulative dose of nasal corticosteroids; ${ }^{\top}$ : per additional $1,000 \mu \mathrm{g} \cdot$ day $^{-1}$ ICS (beclomethasone equivalents); ${ }^{+}$: among controls in category in beclomethasone equivalents. 
response was less obvious than with ICSs when examining the risk of all cataracts, and no increase in risk of cataracts requiring extraction was seen in association with dispensing of NCSs.

For ICSs, the present results are consistent with those of CuMMING et al. [3] and JICK et al. [5], who also found an increase in the risk of cataracts even with low daily doses of ICSs. The strengths of the current study are several. All subjects in the population aged $>65 \mathrm{yrs}$ with more than occasional use of respiratory medications were included. Only first cataracts occurring after a 4-yr period of observation were included so as to avoid masking a relationship to corticosteroid medications, which might have resulted if a cataract had been detected previously and treatment modified as a consequence. Exposure to corticosteroids was as dispensed rather than prescribed medication, thereby increasing the likelihood that patients genuinely took these medications. Owing to the large number of subjects and the frequency of exposure, it was possible to adjust for the concomitant use of other topical and systemic steroids in order to isolate the independent effect of ICSs.

The present study also has several limitations. First, the present results are only applicable to elderly subjects. Secondly, clinical records were not obtained to confirm the diagnosis of cataract. However, restriction of the analysis to cases who underwent extraction within 2 yrs ensures that these cataracts are real and of clinical consequence. The use of corticosteroids has been most closely linked to occurrence of posterior subcapsular cataracts [1, 3]. It was not possible to distinguish between the different types of cataract, and cataracts not influenced by use of corticosteroids were probably included. This decreases the strength of the relationship observed such that the increase in risk of posterior subcapsular cataracts with use of ICSs has probably been underestimated. Although it was possible to measure and control for the effects of important confounders, such as diabetes and other conditions and medications potentially associated with the risk of cataracts, no information on other potential confounding factors, such as smoking and body mass index, was available [2]. Controlling for diabetes and hypertension probably partially accounts for the effect of obesity. Furthermore, since, through reduced physical activity, obesity may result from, rather than cause, cataracts, adjustment for body mass index may not be appropriate. The lack of information on smoking may be more problematic. Partial reassurance is provided by the study of JICK et al. [5], who found that adjustment for smoking did not alter the association between ICSs and risk of cataracts.

Exposure to ICSs and NCSs was examined over the 4-yr period prior to the diagnosis of a first cataract. It is not possible to be certain that the effects observed might not be due to use of oral corticosteroids or higher doses of topical corticosteroids prior to this 4-yr period. The adjustment for the severity of respiratory disease, as reflected by the intensity of use of respiratory medication other than corticosteroids, may partially control for use of corticosteroids in the more distant past. The present results, however, mirror clinical reality in that remote use of medications by patients is often unknown or inaccurate, and it is current doses of medication that are of concern and can be modified.
The present results have important implications for the treatment of asthma and chronic obstructive pulmonary disease in the elderly. For asthma, significant effort needs to be made to reduce the dose of inhaled corticosteroid as much as possible, for example by the use of inhaled corticosteroids in combination with long-acting bronchodilators or anti-leukotrienes [15, 16]. Given the limited efficacy of inhaled corticosteroids in chronic obstructive pulmonary disease $[17,18]$, the balance of evidence in favour of their use is less obvious.

\section{ACKNOWLEDGEMENTS}

The authors would like to acknowledge S. Dellaniello for carrying out the statistical analysis and D. Gaudreau for preparing the final manuscript (both Pharmacoepidemiology Unit, Royal Victoria Hospital, Montreal, QC, Canada).

\section{REFERENCES}

1 Hodge WG, Whitcher JP, Satariano W. Risk factors for agerelated cataracts. Epidemiol Rev 1995; 17: 336-346.

2 Congdon NG. Prevention strategies for age related cataract: present limitations and future possibilities. $\mathrm{Br} J$ Ophthalmol 2001; 85: 516-520.

3 Cumming RG, Mitchell P, Leeder SR. Use of inhaled corticosteroids and the risk of cataracts. N Engl J Med 1997; 337: 8-14

4 Garbe E, Suissa S, LeLorier J. Association of inhaled corticosteroid use with cataract extraction in elderly patients. JAMA 1998; 280: 539-543.

5 Jick SS, Vasilakis-Scaramozza C, Maier WC. The risk of cataract among users of inhaled steroids. Epidemiology 2001; 12: 229-234.

6 National Institutes of Health. National Asthma Education and Prevention Program. Expert Panel Report: Guidelines for the Diagnosis and Management of Asthma Update on Selected Topics - 2002. J Allergy Clin Immunol 2002; 110: Suppl. 5, S141-S219.

7 Lipworth BJ. Systemic adverse effects of inhaled corticosteroid therapy: a systematic review and meta-analysis. Arch Int Med 1999; 159: 941-955.

8 Todd G, Acerini C, Ross-Russell R, Zahra S, Warner J, McCance D. Survey of adrenal crisis associated with inhaled corticosteroids in the United Kingdom. Arch Dis Child 2002; 87: 457-461.

9 Tamblyn R, Lavoie G, Petrella L, Monette J. The use of prescription claims databases in pharmacoepidemiological research: the accuracy and comprehensiveness of the prescription claims database in Quebec. J Clin Epidemiol 1995; 48: 999-1009.

10 Haynes RC. Adrenocorticotropic hormone; adrenocortical steroids and their synthetic analogs; inhibitors of the synthesis and actions of adrenocortical hormones. In: Goodman Gilman A, Rall TW, Nies AS, Taylor P, eds. The Pharmacological Basic of Therapeutics. New York, Pergamon Press, Inc., 1990; pp. 1431-1462.

11 National Heart, Lung, and Blood Institute, National Institutes of Health. National Asthma Education and Prevention Program. Guidelines for the Diagnosis and Management of Asthma. Expert Panel Report 2. NIH 
Publication No. 97-4051. Bethesda, MD, National Heart, Lung, and Blood Institute, 1997.

12 Boulet L-P, Becker A, Bérubé D, Beveridge R, Ernst P. Summary of recommendations from the asthma consensus report, 1999. Can Med Assoc J 1999; 161: Suppl. 11, s1-s62.

13 Garbe E, Suissa S, LeLorier J. Exposure to allopurinol and the risk of cataract extraction in elderly patients. Arch Ophthalmol 1998; 116: 1652-1656.

14 Miettinen O. Estimability and estimation in case-referent studies. Am J Epidemiol 1976; 103: 226-235.

15 Kips JC, Pauwels RA. Long-acting inhaled $\beta_{2}$-agonist therapy in asthma. Am J Respir Crit Care Med 2001; 164: 923-932.
16 Bjermer L, Bisgaard H, Bousquet J, et al. Montelukast and fluticasone compared with salmeterol and fluticasone in protecting against asthma exacerbation in adults: one year, double blind, randomised, comparative trial. BMJ 2003; 327: 891-896.

17 The Lung Health Study Research Group. Effect of inhaled triamcinolone on the decline in pulmonary function in chronic obstructive pulmonary disease. N Engl J Med 2000; 343: 1902-1909.

18 Bourbeau J, Ernst P, Cockcoft D, Suissa S. Inhaled corticosteroids and hospitalisation due to exacerbation of COPD. Eur Respir J 2003; 22: 286-289. 